\title{
Synthesis and evaluation of sodium carboxymethyl cellulose azo polymer for colon specificity
}

\author{
*Mini Ojha' ${ }^{1}$ NV Satheesh Madhav1, Anita Singh² \\ ${ }^{1}$ DIT-Faculty of Pharmacy, Mussorie Diversion Road, Dehradun, Uttarakhand, India \\ ${ }^{2}$ Kumaun University, Nainital, Uttarakhand, India
}

\begin{abstract}
Sodium carboxymethyl cellulose is an excellent pharmaceutical excipient. It possesses good filmability, mucoadhesivity, viscolising capacity and bindability. The current aim of our research work is to synthesize a novel colon targeting polymer by using sodium carboxymethyl cellulose and glycine for colon targeting and to screen its colon specificity by in-vitro release model. Sodium carboxymethyl cellulose was subjected for synthesizing its derivative with glycine using azo linkage. The azo polymeric conjugate was evaluated for its color, solubility, Rf value, melting point, IR and ${ }^{1} \mathrm{HNMR}$ spectral analysis. It was further subjected for evaluating its colon targeting property by in-vitro method using rat fecal matter. The research study revealed that the sodium carboxymethyl cellulose azo derivative showed promising colon specificity for a period of 120 minutes in a controlled manner along with modified solubility. So it can serve as a potential colon targeting polymer.
\end{abstract}

Key Words: Colon targeted delivery, Prodrug, Azo conjugates, Dextran conjugates, Azoreductase, microfloraactivated system.

\section{INTRODUCTION}

Colon targeted drug delivery systems have attracted many researchers due to distinct advantages such as near neutral $\mathrm{pH}$, longer transit time and reduced enzymatic activity. Colon specific drug delivery not only increases the bioavailability of the drug at the target site, but also reduces the side effects (Kinget et al., 1998). In the recent studies, colon targeted drug delivery systems are gaining importance to treat local pathologies of the colon (crohn's disease, inflammatory bowel disease, colonic cancer) and also for the systemic delivery of protein and peptide drugs. This is because the peptide and protein drugs gets destroyed or inactivated in acidic environment of the stomach or by pancreatic enzymes in the small intestine. Various approaches such as pressure dependent, $\mathrm{pH}$-dependent, timedependent and microflora-activated systems have

\footnotetext{
*Corresponding Author:

Mini Ojha, Assistant Professor

DIT-Faculty of Pharmacy

Mussorie Diversion Road

Dehradun, Uttarakhand, India

E-mail:mini_pharma@rediffmail.com

Contact No.: 09411760077
}

been developed for colon specific drug delivery (Chourasia and Jain, 2003). The use of polymers, specifically biodegraded by colonic bacterial enzymes holds great promise for colon targeted drug delivery. Sodium carboxymethyl cellulose is an excellent pharmaceutical excipient. It possesses good filmability, mucoadhesivity, viscolising ability and bindability (Chaudhari et al., 1987). The current aim of our research work is to synthesize a novel colon targeting polymer by using sodium carboxymethyl cellulose and glycine for colon targeting and to screen its colon specificity by in-vitro release model.

\section{MATERIALS AND METHODS}

All chemicals used were of AR grade. Sodium carboxymethyl cellulose, potassium dihydrogen phosphate, sodium nitrate, hydrochloric acid, glycine and sodium hydroxide were purchased from Qualigen Chemicals Pvt. Ltd. The IR spectrum of the synthesized compound was obtained from Laureate Institute; Himachal Pradesh and ${ }^{1} \mathrm{HNMR}$ spectrum was performed in SAIF, Punjab University. 


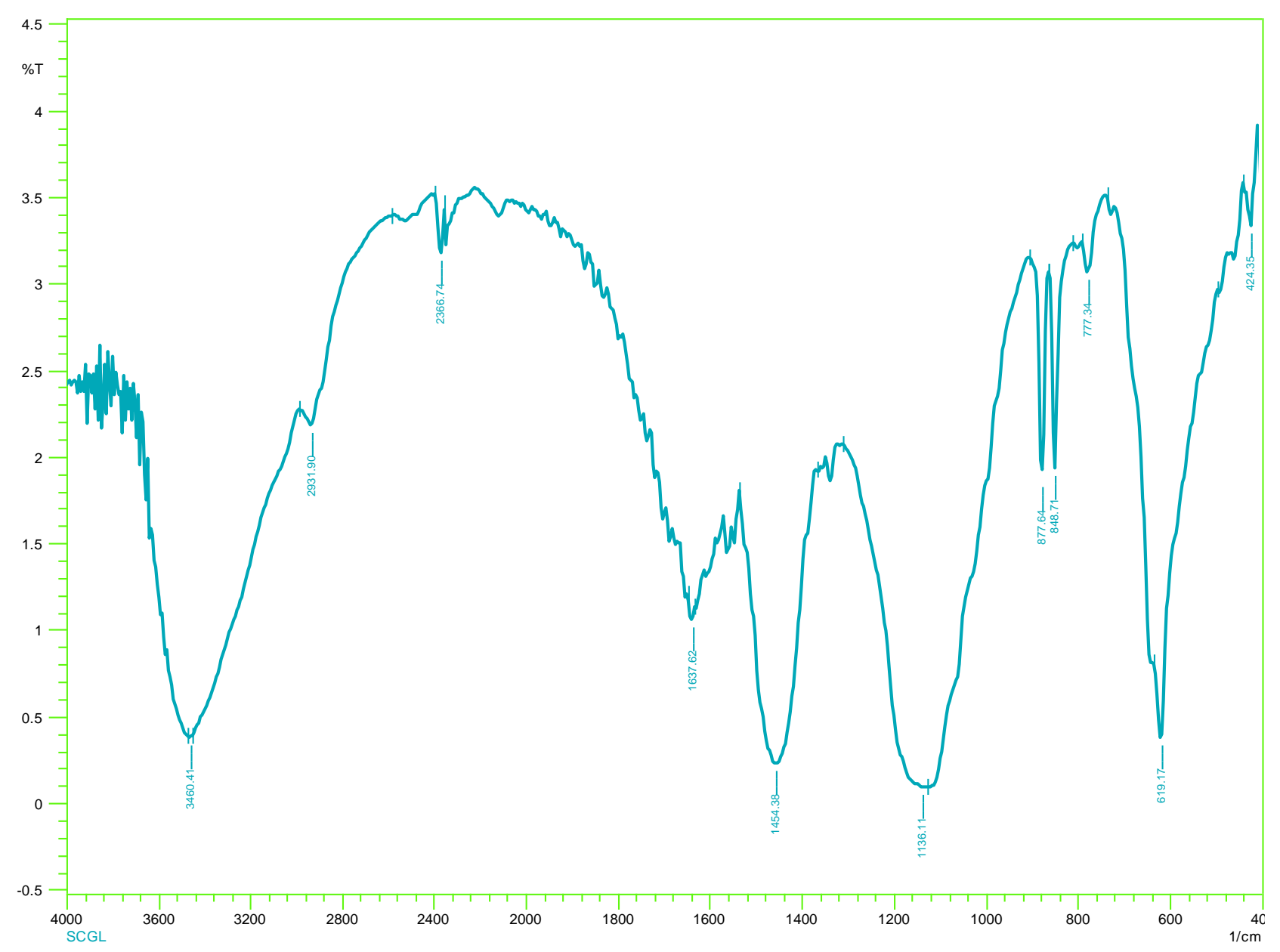

Figure 1: IR of Sodium CMC-Glycine azo conjugate.

\section{Synthesis}

Methyl ester hydrochloride of glycine was prepared by adding thionyl chloride to methanol and then refluxing with amino acid at $60-70^{\circ} \mathrm{C}$ for 7 hours (Dhaneshwar et al., 2009). Diazotization was carried out by reacting with sodium nitrite and hydrochloric acid at $0-5^{\circ} \mathrm{C}$ in ice bath. The diazotized salt was coupled with Sodium carboxymethyl cellulose polymer in $2 \mathrm{M}$ sodium hydroxide under cold conditions by maintaining alkaline and cold environment throughout the reaction. The prepared azo derivative was separated, recrystallized and dried.

\section{Characterization}

The polymer conjugate was subjected for determining its colour, solubility, melting point and Rf value. It was also subjected for IR spectral analysis in Laureate Institute; Himachal Pradesh and ${ }^{1} \mathrm{HNMR}$ spectrum in SAIF; Punjab University.

\section{In vitro Release Study}

The in-vitro release studies on polymer conjugate were conducted in rat fecal matter using Shimadzu $1800 \mathrm{UV}$ spectrophotometer at $304 \mathrm{~nm}$. It was dissolved in a sufficient volume of phosphate buffer ( $\mathrm{pH}$ 7.4) so that the final concentration of solution was $250 \mu \mathrm{g} / \mathrm{ml}$. $1 \mathrm{~g}$ of fresh fecal material of rats was weighed and placed in different sets of test tubes. To each test tube containing a weighed amount of rat fecal matter, $1 \mathrm{ml}$ of the polymer conjugate solution was added and diluted to $5 \mathrm{ml}$ with phosphate buffer. The test tubes were incubated at $37^{\circ} \mathrm{C}$ for different intervals of time. For analysis, the aliquots were removed from the test tubes at different time intervals and estimated directly on double beam UV-spectrophotometer (Jung et al., 2000).

\section{Acute Toxicity Study}

The polymer conjugate was evaluated for acute toxicity study. The study protocol was approved by 


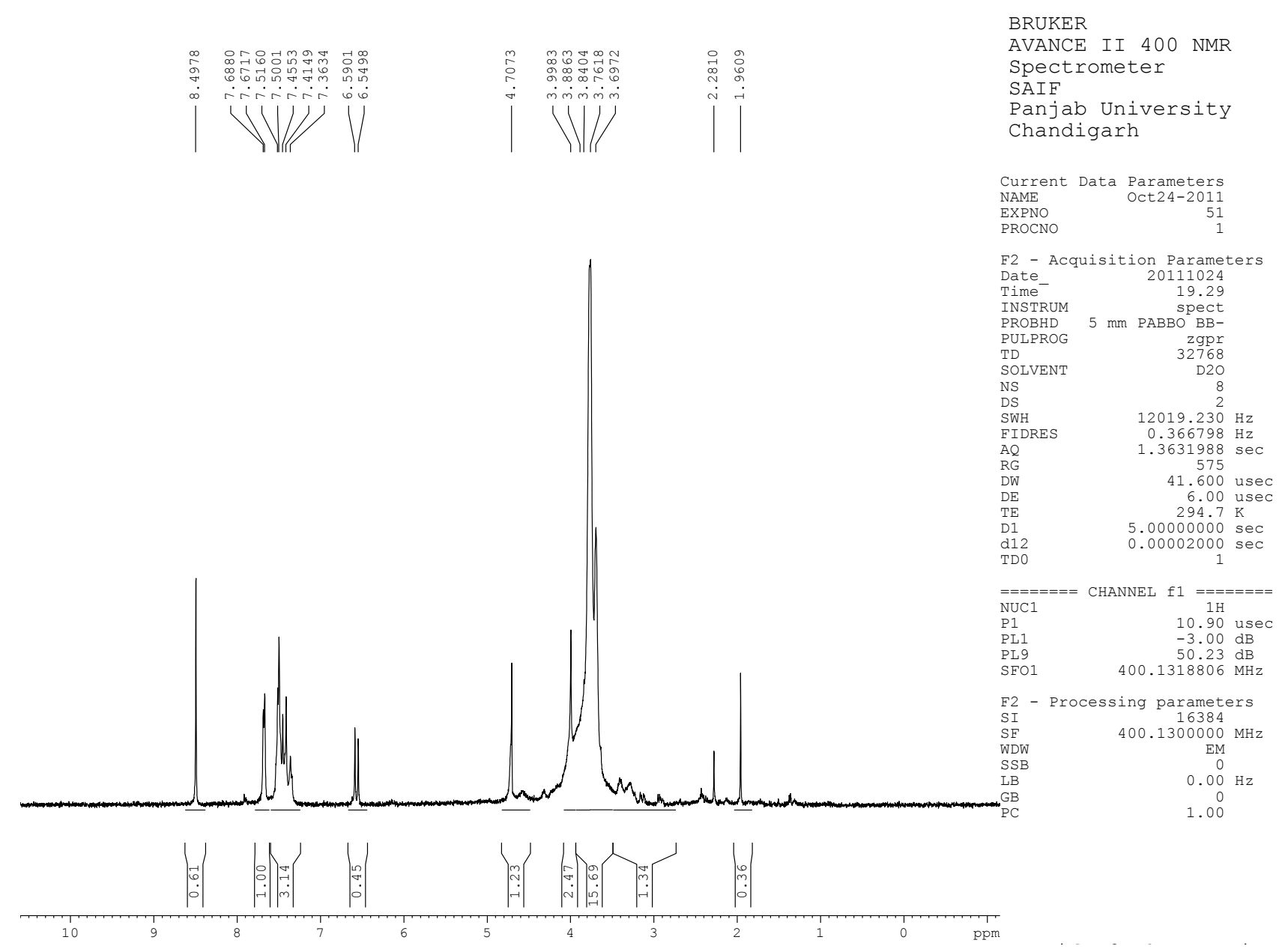

Figure 2: ${ }^{1} \mathrm{HNMR}$ of Sodium CMC-Glycine azo conjugate.

the Institutional Animal Ethical Committee. The procedure followed was as per OECD 423 guidelines. Two groups of 6 albino rats, one for test and other for control, were used for the study. The study was performed by administering the polymer conjugate at $2 \mathrm{~g} / \mathrm{kg}$ body weight for the test group animals. The acute toxicity study was evaluated for a period of 14 days by observing body weight, changes in the skin, corneal reflex, behavioural patterns, and convulsions and compared with the control group animals (Madhav and Shankar, 2011).

\section{RESULTS AND DISCUSSION}

Our experimental results revealed that the synthesized polymer conjugate was deep orange in colour. It was insoluble in $\mathrm{HCl}$ buffer $\mathrm{pH} 1.2$, soluble in phosphate buffer $\mathrm{pH}$ 7.4. The synthesized azo complex had percent yield $85 \%$ and R.F. value 0.68 . Its melting point was $224^{\circ} \mathrm{C}$ (with decomposition).
IR spectroscopy (Figure 1) revealed $3460 \mathrm{~cm}^{-1}(\mathrm{OH}$ stretching), $1637 \mathrm{~cm}^{-1}(\mathrm{C}=\mathrm{C}$ stretching aromatic ring, $1454 \mathrm{~cm}^{-1} \quad\left(-\mathrm{N}=\mathrm{N}-\right.$ stretching), $1136 \mathrm{~cm}^{-1} \quad$ (C-N stretching), 777, $619 \mathrm{~cm}^{-1}(\mathrm{CH}$ bending aromatic ring). ${ }^{1} \mathrm{H}$ NMR (Figure 2) showed chemical shift at $\delta$

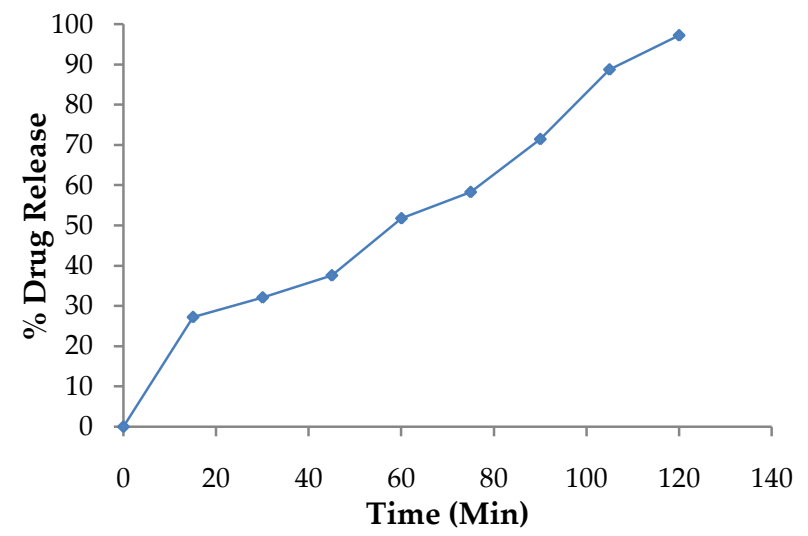

Figure 3: In-vitro release of Sodium CMC-Glycine azo conjugate. 
1.9 (- $\mathrm{CH}$ saturated proton), $\delta 2.2(-\mathrm{C} \equiv \mathrm{CH}$, acetylenic proton), $\delta$ 3.6-3.9 $\left(\mathrm{CH}_{3} \mathrm{OR}\right.$, ether proton), $\delta 4.7$ ($\mathrm{C}=\mathrm{CH}$, vinylic proton), $\delta 6.5(\mathrm{Ar}-\mathrm{H}$, aromatic proton), $\delta$ 7.3-7.6, 8.4 (Ar-OH, phenolic proton). The in-vitro release studies on azo polymer reveal that the synthesized polymer conjugate showed promising colon specificity with $97.2 \%$ release after 120 minutes (Figure 3).

\section{CONCLUSION}

The conclusion was drawn that the synthesized hydroxypropyl methylcellulose azo derivative can serve as a potential colon targeting polymer and it can be used as an excipient for formulating colon targeted drug delivery systems.

\section{REFERENCES}

Chaudhari, S.N.K., Gounden, C., Srinivasan G., Ekkundi, V.S. (1987) High resolution 13C-NMR spectroscopy of sodium carboxymethyl cellulose. Journal of Polymer Science. Volume 25, Issue 1, Pages 337-342.

Chourasia, M.K., Jain, S.K. (2003) Pharmaceutical approaches to colon targeted drug delivery systems. J Pharm Pharmaceut Sci, 6(1): 33-66.

Dhaneshwar, S., Kandpal, M. and Vadnerkar, G. (2009) Lglutamine conjugate of meselamine: a novel approach for targeted delivery to colon. J. Drug Del. Sci. Tech., 19 (1) 6772 .

Jung Y.N., Lee J.S., Kim Y.M. (2000) Synthesis and in vitro/ in vivo evaluation of 5-aminosalicyl-glycine as a colon specific prodrug of 5-aminosalicylic acid. J. Pharm. Sci., Volume 89, Issue 5, Pages 594-601. [DOI]

Kinget R., Kalala W., Vervoort L., Van den M.G., (1998) Colonic drug targeting. J. Drug Target, Volume 6, Pages 129-149. [DOI] PMid: 9886237

Madhav, N.V.S. , Shankar, M.S.U. (2011) A novel smart mucoadhesive biomaterial from Lallimantia royalena seed coat. Science Asia, Volume 37, Pages 69-71. [DOI] 